\title{
GERMINAÇÃO DE SEMENTES E CRESCIMENTO DE PLÂNTULAS DE BRASSICA CHINENSIS L. VAR. PARACHINENSIS (BAILEY) SINSKAJA (COUVE-DA-MALÁSIA) ${ }^{1}$
}

\author{
WANESSA RESENDE FERREIRA ${ }^{2}$ e MARLI A. RANAL ${ }^{3}$
}

\begin{abstract}
RESUMO - Brassica chinensis var. parachinensis, introduzida no Brasil em 1992, apresenta alto teor de vitamina A e ciclo curto. As sementes foram submetidas a 24 tratamentos em laboratório e $12 \mathrm{em}$ campo, com o objetivo de avaliar o padrão de germinação e o crescimento das plântulas. Em laboratório, as sementes foram indiferentes à luz e mostraram baixa sensibilidade à ação escarificante do hipoclorito de sódio. Ácido giberélico, $\mathrm{KNO}_{3}$, escarificação e estratificação não modificaram sua germinabilidade (96-100\%) nem o tempo médio de germinação (1-1,28 dias) em relação ao controle. Em condições de campo os maiores valores de emergência $(89,2-96,4 \%)$ e os maiores índices de velocidade de emergência $(14,2-17,4)$ ocorreram em solo com adubação mineral, entre 0,5 e $1,5 \mathrm{~cm}$ de profundidade. Os menores tempos médios de emergência foram registrados entre 0,5 e 1,5 cm de profundidade (2,90-3,97 dias), com os três adubos testados (mineral, esterco de gado e de galinha). As plântulas se mostraram sensíveis ao hipoclorito de sódio, com redução significativa do hipocótilo e da raiz primária. A estratificação das sementes por 24 horas estimulou o crescimento da raiz primária, o que beneficia o estabelecimento da plântula no solo.
\end{abstract}

Termos para indexação: Brassicaceae, germinabilidade, hortaliça.

\section{SEED GERMINATION AND SEEDLING GROWTH OF BRASSICA CHINENSIS L. VAR. PARACHINENSIS (BAILEY) SINSKAJA (FLOWERING WHITE CABBAGE)}

\begin{abstract}
Brassica chinensis var. parachinensis was introduced in Brazil in 1992. This variety presents a high content of vitamin A and a short life cycle. Seeds were submitted to 24 treatments in laboratory conditions and 12 treatments in field conditions with the objective of evaluating the germination pattern and seedling growth. In laboratory conditions, seed germination was light independent and the germinability was reduced in $12 \%$ by the action of sodium hypochlorite scarification. Gibberellic acid, $\mathrm{KNO}_{3}$, mechanical scarification and stratification did not modify the germinability of the seeds (96-100\%) neither the average time of germination (1-1.28 days) in relation to the control treatment. In field conditions the highest values of emergence (89.2-96.4\%) and the highest rates of emergence velocity (14.2-17.4) occurred in soil with mineral fertilization, between 0.5 and $1.5 \mathrm{~cm}$ depth. Shorter average times of emergence were registered from 0.5 to $1.5 \mathrm{~cm}$ depth (2.90-3.97 days), for the three fertilizers tested (mineral fertilization, cattle manure, and chicken manure). Seedlings were sensitive to sodium hypochlorite with significant reduction of hypocotyl and primary root. Stratification of seeds by 24 hours stimulated growth of primary roots improving the establishment of seedling in the soil.
\end{abstract}

Index terms: Brassicaceae, germinability, vegetable.

${ }^{1}$ Aceito para publicação em 27 de fevereiro de 1998. Extraído da Monografia apresentada pela primeira autora, para obtenção do grau de Engenheira Agrônoma, na Universidade Federal de Uberlândia (UFU).

${ }^{2}$ Eng 1 Agr ${ }^{\mathrm{a}}$, Rua Santos Dumont 935, CEP 38400-026 Uberlândia, MG.

${ }^{3}$ Bióloga, Drª , Profa Adjunta, Dep. de Biociências, UFU, Caixa Postal 593, CEP 38400-902 Uberlândia, MG. E-mail: ranal@ufu.br

\section{INTRODUÇÃO}

$\mathrm{O}$ rápido crescimento populacional tem desencadeado estudos visando ao aumento na produtividade agrícola e à descoberta de fontes não-convencionais de alimento.

Entre as plantas cultivadas, as hortaliças representam o maior grupo, com mais de 100 espécies, a maioria delas essenciais à alimentação humana por 
serem importantes fontes de vitaminas e sais minerais (Cobbe \& Jabuonski, 1993). Problemas de avitaminose que ocorrem especialmente na população de baixa renda podem ser solucionados com hortaliças, daí o interesse em estudos de melhoramento genético das cultivares já lançadas no mercado, da descoberta de espécies com potencial agronômico ou da importação de hortaliças de outras partes do mundo. Outro fator importante é que as hortaliças têm capacidade de produzir grande quantidade de alimento por área cultivada (Costa \& Resende, 1983).

Das espécies oleráceas cultivadas no Brasil, as brassicáceas constituem a família mais numerosa, destacando-se na região centro-sul. As mais cultivadas são o repolho, a couve-flor, a couve-manteiga e o brócolos (Filgueira, 1982). Em geral, seu custo de produção é relativamente baixo quando comparado ao de outras espécies hortícolas (Kimoto, 1993).

Além da relevante importância como hortaliças, algumas brassicáceas também são utilizadas como adubos verdes, forragem, condimento, fonte de óleo e na fabricação de picles e chucrutes (Vilella, 1983; Opeña et al., 1988).

De 1990 a 1996, o volume total das principais brássicas comercializadas na Ceasa de Uberlândia, $\mathrm{MG}$, apresentou crescimento contínuo, atingindo o montante de 42.992 toneladas. Desse montante, o repolho representou $89,1 \%$, a couve-flor $10,2 \%$, a couve-manteiga $0,3 \%$, e o brócolos $0,5 \%$.

Brassica chinensis L. var. parachinensis (Bailey) Sinskaja é uma das quatro variedades de Brassica chinensis Juslenius reconhecidas por Mansfeld em 1959, sendo denominada "mock pak-choi" (Bailey, 1930), "flowering white cabbage", "paak ts'oi sum" (Herklots, 1972), "tsoi sum" (Hill, 1990) ou "couveda-malásia”. Esta última denominação foi adotada pelo Dr. W.E. Kerr, responsável pela introdução dessa variedade no Brasil em 1992, no município de Uberlândia. É uma hortaliça anual ou bianual (Herklots, 1972), de crescimento rápido (Lee, 1982), própria para o consumo de folhas, caule e flores. $\mathrm{Na}$ Ásia, onde seu consumo é bastante acentuado, especialmente na China Central (Nishi, 1980), é cultivada ao longo do ano, com tendência a encurtar o ciclo de cultivo durante verões úmidos, exigindo então solos mais férteis e bem drenados (Herklots, 1972).
A difusão das espécies, subespécies e variedades de Brassica por interferência do homem para áreas mais distantes de seu centro de origem, o aparecimento de cultivares mais produtivas e selecionadas para tolerar regiões mais quentes e a hibridização que ocorre naturalmente nesses grupos, tornou sua taxonomia bastante complexa.

Nesse sentido, é importante salientar que essa variedade é considerada por Opeña et al. (1988) como Brassica campestris subsp. parachinensis. Segundo eles, essa subespécie é considerada como derivada de Brassica campestris subsp. chinensis, diferindo desta pela produção de grande número de ramos nas axilas das folhas. Brassica campestris, de acordo com os citados autores, originou-se em áreas do Mediterrâneo e foi introduzida na Ásia através do norte europeu, onde ocorreram as mudanças mais significantes em sua forma, estrutura e produtividade. Tanto Brassica campestris subsp. pekinensis (com cabeça) como B. campestris subsp. chinensis (sem cabeça) têm-se espalhado nos últimos anos fora da Ásia e sua popularidade entre os povos não-orientais, especialmente da América do Norte e oeste europeu, tem aumentado gradativamente.

As couves chinesas, de forma geral, são importantes fontes de cálcio e vitamina C. De acordo com a Food Composition Table for Use in East Asia, 1972, Brassica campestris subsp. parachinensis apresenta em $100 \mathrm{~g}$ da porção comestível, 2,1 g de proteína, $109 \mathrm{mg}$ de cálcio, 3,1 mg de ferro, $2045 \mu \mathrm{g}$ (eq. caroteno) de vitamina A e $60 \mathrm{mg}$ de vitamina C (Opeña et al., 1988).

Parece existir uma relação entre a cor da semente e a distribuição geográfica das espécies da tribo Brassiceae (Gómez-Campo, 1980). Com poucas exceções, espécies do Mediterrâneo normalmente apresentam sementes de coloração ocre ou castanha, as euro-siberianas, coloração castanho-escura ou preta, e as espécies de regiões desérticas, coloração amarelada. As sementes de Brassica chinensis var. parachinensis são esféricas, de tegumento liso, com marcante heterogeneidade na coloração, que vai de ocre a castanha.

O comportamento fotoblástico das sementes é importante característica na determinação da distribuição espacial de uma espécie no ambiente. Tal característica pode ser alterada tanto pelas condições 
ecológicas a que a planta-mãe é submetida no período de maturação das sementes como também pelas condições a que as sementes são submetidas no armazenamento (Labouriau, 1983). O fotoblastismo positivo das sementes pode desaparecer com processos de escarificação, estratificação, por ação da temperatura, armazenamento a seco, com aplicação de nitrato de potássio ou de giberelinas (Bewley \& Black, 1982; Labouriau, 1983).

Os nitritos, os nitratos e as giberelinas são utilizados em sementes de algumas espécies para estimular a germinação ou como tratamentos químicos para quebra de dormência, podendo substituir o efeito da luz ou da estratificação (Bewley \& Black, 1982, 1994; Labouriau, 1983). Sementes do grupo Brassica oleracea, incluindo a couve-flor, são ocasionalmente dormentes e podem germinar com a aplicação de ácido giberélico a 10 e 15 ppm (Solanki \& Joshi, 1985). Segundo Hilhorst (1990a, 1990b), os nitratos podem funcionar como cofator para a ação do fitocromo, facilitando assim a germinação pela síntese endógena de hormônios necessários à retomada do desenvolvimento pelo embrião.

O uso de solução de hipoclorito de sódio como forma de assepsia de unidades de dispersão em laboratórios é muito comum, mas pode afetar a germinação. Há vários registros referentes à quebra de dormência ou estímulo da germinação resultantes da escarificação feita com a aplicação dessa substância em diferentes concentrações, em espécies variadas (Frank \& Larson, 1970; Emal \& Conard, 1973; Okonkwo \& Nwoke, 1975; French \& Sherman, 1976). Segundo Hsiao et al. (1981), a escarificação feita pelo hipoclorito de sódio além de aumentar a permeabilidade do tegumento ao oxigênio, água e solutos, também pode facilitar a remoção ou oxidação de inibidores de germinação, o que levou Bewley \& Black (1994) a considerar essa substância como um agente químico oxidante, usado para quebra de dormência em sementes. A aplicação de hipoclorito de sódio pode ainda evitar a termodormência em sementes, o que é extremamente importante para hortaliças cultivadas em regiões mais quentes (Drew \& Brocklehurst, 1984). Por outro lado, a ação prolongada do hipoclorito de sódio ou sua utilização em altas concentrações pode induzir a dormência de sementes de algumas espécies (McCollum \& Linn, 1955; Hsiao, 1979; Hsiao et al., 1981).
Neste trabalho são apresentadas informações referentes ao padrão de germinação das sementes de Brassica chinensis var. parachinensis, em condições de laboratório e de campo, bem como informações sobre as plântulas produzidas em laboratório, o que poderá fornecer subsídios para viabilizar a produção em escala comercial.

\section{MATERIAL E MÉTODOS}

As sementes de Brassica chinensis var. parachinensis utilizadas nos experimentos foram obtidas no Laboratório de Genética da Universidade Federal de Uberlândia, MG, a partir de semeaduras sucessivas de material trazido da Malásia por Warwick Estevan Kerr, em 1992.

O clima da região de Uberlândia é do tipo Aw, segundo o sistema de classificação de Köppen, com verão chuvoso de outubro a março e inverno seco de abril a setembro (Schiavini, 1992).

\section{Experimento em condições de laboratório}

O experimento foi realizado no período de 21 a 28 de setembro de 1992, utilizando sementes produzidas nos meses de junho e julho do mesmo ano. Durante a condução do experimento, a temperatura média mínima registrada no laboratório foi de $20^{\circ} \mathrm{C}$, e a média máxima, de $24,6^{\circ} \mathrm{C}$. As placas-de-Petri foram mantidas à irradiância média de $2088,38 \pm 130,41 \mu \mathrm{W} / \mathrm{cm}^{2}$, fornecida por duas lâmpadas fluorescentes GE de $20 \mathrm{~W}$. As medidas de irradiância foram feitas na altura das placas, com uma célula solar desenvolvida pela Heliodinâmica, SP, acoplada a um multímetro digital TOPIS, modelo MIC-2200A. Nos tratamentos mantidos no escuro, as placas-de-Petri foram envolvidas em sacos de plástico pretos.

As sementes foram distribuídas em placas-de-Petri de $10 \mathrm{~cm}$ de diâmetro, forradas com papel de filtro, em 24 tratamentos, com cinco repetições de 50 sementes, sendo: 1) luz fluorescente contínua, substrato umedecido com água; 2) escuro, substrato umedecido com água; 3) luz fluorescente contínua, substrato umedecido com solução de hipoclorito de sódio com $0,14 \%$ de cloro ativo; 4 ) escuro, substrato umedecido com solução de hipoclorito de sódio com $0,14 \%$ de cloro ativo; 5 ) luz fluorescente contínua, substrato umedecido com água, sementes escarificadas mecanicamente por fricção entre duas lixas d'água no 324 -- após a escarificação as sementes foram examinadas sob estereomicroscópio para a retirada daquelas com danos no embrião; 6 a 12) sementes estratificadas, substrato umedecido com água, mantidas a $4^{\circ} \mathrm{C}$ no escuro durante 6,12 , $18,24,36,48$, e 72 horas -- após esses períodos as placas 
contendo as sementes foram retiradas da geladeira e mantidas sob luz fluorescente contínua; 13) luz fluorescente contínua, substrato umedecido com solução de $\mathrm{KNO}_{3}$ a $0,2 \%$; 14) escuro, substrato umedecido com solução de $\mathrm{KNO}_{3}$ a $0,2 \% ; 15$ a 19) luz fluorescente contínua, substrato umedecido com solução de $\mathrm{GA}_{3}$ a $0,001,0,01,0,1,1,0$ e $10,0 \mu \mathrm{g} / \mathrm{mL} ; 20$ a 24) escuro, substrato umedecido com solução de $\mathrm{GA}_{3}$ a $0,001,0,01,0,1,1,0$ e $10,0 \mu \mathrm{g} / \mathrm{mL}$.

A solução de hipoclorito de sódio foi preparada, imediatamente antes de ser utilizada, a partir de água sanitária comercial (clorox) com $2 \%$ de cloro ativo, diluída em água, na proporção de 1:24, obtendo-se uma solução final com $0,14 \%$ de cloro ativo.

As placas-de-Petri contendo as sementes dos tratamentos mantidos sob luz fluorescente contínua foram umedecidas com $4 \mathrm{~mL}$ e as mantidas no escuro com $5 \mathrm{~mL}$ de água destilada ou das soluções testadas. Sempre que necessário, as placas mantidas sob luz foram umedecidas com água destilada.

O critério de germinação adotado foi a protrusão de qualquer parte do embrião. As contagens foram feitas sem retirada das sementes germinadas e sempre no mesmo horário, a cada 24 horas, exceto nos tratamentos mantidos no escuro em que foi feita uma única observação, no sétimo dia após a instalação do experimento.

Também sete dias após iniciado o experimento, foram feitas medidas do hipocótilo e da raiz primária de 20 plântulas obtidas nos tratamentos com $\mathrm{KNO}_{3}$, estratificação por 24 horas, com hipoclorito de sódio e com $\mathrm{GA}_{3} 0,001 \mu \mathrm{g} / \mathrm{mL}$, todos mantidos sob luz fluorescente contínua.

As medidas foram feitas com auxílio de um paquímetro, tomando-se como referência a base do coleto. As medidas do hipocótilo foram feitas até a base dos cotilédones e da raiz primária até o ápice desta.

O delineamento experimental foi o inteiramente casualizado (Banzatto \& Kronka, 1989). O tempo médio de germinação foi calculado de acordo com Labouriau (1983), sendo $\overline{\mathrm{t}}=\sum$ niti $/ \sum$ ni $(\overline{\mathrm{t}}=$ média ponderada; $\mathrm{t}=$ tempo de germinação, em dias, contado a partir da instalação do experimento; $\mathrm{ni}=$ número de sementes germinadas no tempo ti, usado como peso de ponderação dos ti). A análise de variância dos tempos médios de germinação foi feita utilizando-se o Statistical Package of Social Science (SPSS V.H.).

\section{Experimento em condições de campo}

O experimento foi instalado no dia 20 de dezembro de 1992, em local de meia sombra, numa área subdividida com chapas de zinco e formando células de $248,4 \mathrm{~cm}^{2}$, para verificar a melhor profundidade de semeadura, em solo com diferentes tipos de adubação. Foram testadas as pro- fundidades de $0,5,1,0,1,5$ e 2,0 cm, com cinco repetições de 50 sementes. Para cada profundidade, as sementes foram mantidas em solo adubado com $2 \mathrm{~kg} / \mathrm{m}^{2}$ de esterco de gado; $0,5 \mathrm{~kg} / \mathrm{m}^{2}$ de esterco de galinha e com adubo mineral na dosagem de $833 \mathrm{~kg} / \mathrm{ha}$ de superfosfato simples, $150 \mathrm{~kg} / \mathrm{ha}$ de sulfato de amônio e $150 \mathrm{~kg} / \mathrm{ha}$ de cloreto de potássio, seguindo as recomendações feitas pelo Laboratório de Solos da Universidade Federal de Uberlândia, totalizando 12 tratamentos. A irrigação foi feita diariamente.

As temperaturas médias mínima e máxima registradas no município de Uberlândia, no período de condução do experimento, foram de 19,0 e $29,4^{\circ} \mathrm{C}$, respectivamente.

$\mathrm{O}$ delineamento experimental foi o inteiramente casualizado, num esquema fatorial $3 \times 4$. O tempo médio de emergência foi calculado utilizando-se a fórmula proposta por Labouriau (1983) para obtenção do tempo médio de germinação de sementes $\left(\overline{\mathrm{t}}=\sum\right.$ niti/ $\sum$ ni, onde $\overline{\mathrm{t}}=$ média ponderada; $\mathrm{ti}=$ tempo de emergência, em dias, contado a partir da instalação do experimento; $n i=$ número de plântulas emergidas (emergência dos cotilédones) no tempo ti). As contagens foram feitas a cada 24 horas, sem retirada das plântulas. O índice de velocidade de emergência (IVE) foi calculado segundo Maguire (1962).

\section{RESULTADOS E DISCUSSÃO}

\section{Germinação das sementes}

O tempo médio de germinação das sementes mantidas em condições de laboratório foi de 1 a 2,03 dias, sendo o maior tempo o de sementes tratadas com hipoclorito de sódio (Tabela 1).

Com exceção das sementes mantidas em solução de hipoclorito de sódio que apresentaram a menor porcentagem de germinação, não houve diferença significativa nos demais tratamentos, com germinabilidade entre 96 e 100\% (Tabela 2).

Os resultados revelam que as sementes de couve-da-malásia foram indiferentes à luz nas condições do experimento. Além disso, apresentaram germinação alta e sincronizada em todos os tratamentos, o que indica a possibilidade de serem utilizadas para produção de mudas em escala comercial.

Esse comportamento não é característico de todas as brássicas. Sementes de Brassica chinensis mantidas por 14 dias em regime de temperaturas alternantes de $20^{\circ} \mathrm{C}$ e $30^{\circ} \mathrm{C}$ por 16 horas e 8 horas, respectivamente, não germinam no escuro (Ellis 
et al., 1989). Os autores verificaram que a adição de $\mathrm{KNO}_{3}\left(2 \times 10^{-2} \mathrm{M}\right)$ não exerceu nenhum efeito nessa condição e inibiu a germinação de sementes na presença de luz, enquanto a aplicação de $\mathrm{GA}_{3}$ $\left(3 \times 10^{-4} \mathrm{M}\right)$ aumentou significativamente a germinação das sementes mantidas no escuro.

A ação escarificante da solução de hipoclorito de sódio em sementes, verificada em várias espécies (McCollum \& Linn, 1955; Frank \& Larson, 1970; Emal \& Conard, 1973; French \& Sherman, 1976; Hsiao, 1979; Hsiao et al., 1981; Drew \& Brocklehurst, 1984), não se mostrou drástica nas sementes da espécie estudada. A redução na germinabilidade foi de aproximadamente $12 \%$ em relação ao controle, com atraso de um dia, enquanto em sementes de alface cv. Moreninha-de-Uberlândia, com 101 dias de idade, a redução foi de $95 \%$, com atraso de 16 dias no tempo médio de germinação em relação ao controle (Carnelossi et al., 1995).

TABELA 1. Tempo médio de germinação de sementes de Brassica chinensis var. parachinensis, mantidas em diferentes condições de laboratório ${ }^{1}$.

\begin{tabular}{|c|c|}
\hline Tratamento & $\begin{array}{l}\text { Tempo médio de } \\
\text { germinação (dias) }\end{array}$ \\
\hline Água (controle) & $1,130 \pm 0,020 \mathrm{abc}$ \\
\hline Hipoclorito de sódio & $2,030 \pm 0,090 \mathrm{e}$ \\
\hline Escarificação & $1,200 \pm 0,040 \mathrm{bcd}$ \\
\hline Estratificação 6 horas & $1,060 \pm 0,020 \mathrm{ab}$ \\
\hline Estratificação 12 horas & $1,350 \pm 0,040 \mathrm{~d}$ \\
\hline Estratificação 18 horas & $1,050 \pm 0,003 \mathrm{ab}$ \\
\hline Estratificação 24 horas & $1,010 \pm 0,006 \mathrm{a}$ \\
\hline Estratificação 36 horas & $1,050 \pm 0,003 \mathrm{ab}$ \\
\hline Estratificação 48 horas & $1,000 \pm 0,000 \mathrm{a}$ \\
\hline Estratificação 72 horas & $1,004 \pm 0,004 a$ \\
\hline $\mathrm{KNO}_{3}$ & $1,280 \pm 0,060 \mathrm{~cd}$ \\
\hline $\mathrm{GA}_{3} 0,001 \mu \mathrm{g} / \mathrm{mL}$ & $1,060 \pm 0,020 \mathrm{ab}$ \\
\hline $\mathrm{GA}_{3} 0,01 \mu \mathrm{g} / \mathrm{mL}$ & $1,110 \pm 0,030 \mathrm{ab}$ \\
\hline $\mathrm{GA}_{3} 0,1 \mu \mathrm{g} / \mathrm{mL}$ & $1,010 \pm 0,006 \mathrm{a}$ \\
\hline $\mathrm{GA}_{3} 1 \mu \mathrm{g} / \mathrm{mL}$ & $1,080 \pm 0,030 \mathrm{ab}$ \\
\hline $\mathrm{GA}_{3} 10 \mu \mathrm{g} / \mathrm{mL}$ & $1,020 \pm 0,010 \mathrm{a}$ \\
\hline $\mathrm{F}$ & $52,52^{* *}$ \\
\hline G.L. & $15 ; 3934$ \\
\hline C.V. $(\%)$ & 45,97 \\
\hline \multicolumn{2}{|c|}{$\begin{array}{l}\text { Valores seguidos de letras iguais na coluna não diferem significativa- } \\
\text { mente a } 5 \% \text { pelo teste de Tukey. } \\
\text { Média } \pm \text { erro padrão. } \\
\text { Significativo a } 1 \% \text {. }\end{array}$} \\
\hline
\end{tabular}

O tempo médio de emergência das plântulas em condições de campo foi de 2,90 a 4,18 dias (Tabela 3). Os menores valores foram registrados entre $0,5 \mathrm{e}$ $1,5 \mathrm{~cm}$ de profundidade com os três adubos testados. Os índices de velocidade de emergência variaram entre 7,63 e 17,43, sendo os maiores valores observados entre 0,5 e $1,5 \mathrm{~cm}$ de profundidade, em solo com adubação mineral (Tabela 4). Os maiores valores de emergência (89-96\%) foram registrados entre 0,5 e 1,5 cm de profundidade, com adubação mineral (Tabela 5).

A 2,0 cm de profundidade o tempo médio de emergência, o índice de velocidade de emergência e os

TABELA 2. Germinabilidade de sementes de Brassica chinensis var. parachinensis, mantidas em diferentes condições de laboratório, sete dias após a instalação do experimento ${ }^{1}$.

\begin{tabular}{|c|c|c|}
\hline Tratamento & $\begin{array}{c}\text { Germinabilidade } \\
(\%)^{2}\end{array}$ & $\begin{array}{c}\text { Valor } \\
\text { angular }^{3}\end{array}$ \\
\hline Água (controle) & $99,6 \pm 0,40$ & $88,37 \mathrm{ab}$ \\
\hline Água, escuro & $99,6 \pm 0,40$ & $88,37 \mathrm{ab}$ \\
\hline Hipoclorito sódio & $87,2 \pm 6,28$ & $73,83 \mathrm{~d}$ \\
\hline Hipoclorito sódio, escuro & $92,0 \pm 3,90$ & $76,26 \mathrm{~cd}$ \\
\hline Escarificação & $95,6 \pm 0,98$ & $78,16 \mathrm{bcd}$ \\
\hline Estratificação 6 horas & $99,6 \pm 0,40$ & $88,37 \mathrm{ab}$ \\
\hline Estratificação 12 horas & $99,6 \pm 0,40$ & $88,37 \mathrm{ab}$ \\
\hline Estratificação 18 horas & $99,6 \pm 0,40$ & $88,37 \mathrm{ab}$ \\
\hline Estratificação 24 horas & $100,0 \pm 0,00$ & $90,00 \mathrm{a}$ \\
\hline Estratificação 36 horas & $98,8 \pm 0,80$ & $86,07 \mathrm{abc}$ \\
\hline Estratificação 48 horas & $100,0 \pm 0,00$ & $90,00 \mathrm{a}$ \\
\hline Estratificação 72 horas & $100,0 \pm 0,00$ & $90,00 \mathrm{a}$ \\
\hline $\mathrm{KNO}_{3}$ & $99,6 \pm 0,40$ & $88,37 \mathrm{ab}$ \\
\hline $\mathrm{KNO}_{3}$, escuro & $100,0 \pm 0,00$ & $90,00 \mathrm{a}$ \\
\hline $\mathrm{GA}_{3} 0,001 \mu \mathrm{g} / \mathrm{mL}$ & $99,6 \pm 0,40$ & $88,37 \mathrm{ab}$ \\
\hline $\mathrm{GA}_{3} 0,01 \mu \mathrm{g} / \mathrm{mL}$ & $99,2 \pm 0,76$ & $87,69 \mathrm{abc}$ \\
\hline $\mathrm{GA}_{3} 0,1 \mu \mathrm{g} / \mathrm{mL}$ & $99,6 \pm 0,40$ & $88,37 \mathrm{ab}$ \\
\hline $\mathrm{GA}_{3} 1 \mu \mathrm{g} / \mathrm{mL}$ & $100,0 \pm 0,00$ & $90,00 \mathrm{a}$ \\
\hline $\mathrm{GA}_{3} 10 \mu \mathrm{g} / \mathrm{mL}$ & $100,0 \pm 0,00$ & $90,00 \mathrm{a}$ \\
\hline $\mathrm{GA}_{3} 0,001 \mu \mathrm{g} / \mathrm{mL}$, escuro & $99,6 \pm 0,40$ & $88,37 \mathrm{ab}$ \\
\hline $\mathrm{GA}_{3} 0,01 \mu \mathrm{g} / \mathrm{mL}$, escuro & $99,6 \pm 0,40$ & $88,37 \mathrm{ab}$ \\
\hline $\mathrm{GA}_{3} 0,1 \mu \mathrm{g} / \mathrm{mL}$, escuro & $99,6 \pm 0,40$ & $88,37 \mathrm{ab}$ \\
\hline $\mathrm{GA}_{3} 1 \mu \mathrm{g} / \mathrm{mL}$, escuro & $99,2 \pm 0,49$ & $86,75 \mathrm{abc}$ \\
\hline $\mathrm{GA}_{3} 10 \mu \mathrm{g} / \mathrm{mL}$, escuro & $100,0 \pm 0,00$ & $90,00 \mathrm{a}$ \\
\hline $\mathrm{F}$ & & $3,98 * *$ \\
\hline G.L. & & $23 ; 119$ \\
\hline C.V. $(\%)$ & & 5,70 \\
\hline
\end{tabular}

1 Valores seguidos de letras iguais na coluna não diferem significativamente a $5 \%$ pelo teste de Tukey.

Média \pm erro padrão.

3 Dados transformados em arco seno para análise.

** Significativo a $1 \%$. 
valores de emergência final independem do tipo de adubo aplicado.

Apesar de ter sido registrada alta porcentagem de emergência a $0,5 \mathrm{~cm}$, observações de campo permitiram verificar que as plântulas oriundas da semeadura a essa profundidade apresentaram curvatura no caule, com tombamento, produzindo mudas com morfologia inadequada para o plantio. Nessa profundidade, houve também alta mortalidade das plântulas, por ressecamento, em decorrência da exposição excessiva do sistema radicular.

A maior porcentagem de emergência de plântulas e o maior índice de velocidade de emergência registrados no tratamento com adubação mineral podem estar relacionados com a maior densidade do substrato e maior cobertura decorrente do tamanho reduzido de suas partículas, o que evita a exposição das sementes por ocasião das irrigações, além de

TABELA 3. Tempo médio de emergência de plântulas de Brassica chinensis var. parachinensis (média \pm erro padrão), em diferentes condições de campo ${ }^{1}$.

\begin{tabular}{lcccc}
\hline Adubação & \multicolumn{4}{c}{ Profundidade de semeadura $(\mathrm{cm})$} \\
\cline { 2 - 4 } & 0,5 & 1,0 & 1,5 & 2,0 \\
\hline Mineral & $2,90 \pm 0,06 \mathrm{aA}$ & $3,80 \pm 0,07 \mathrm{bB}$ & $3,63 \pm 0,06 \mathrm{bA}$ & $4,02 \pm 0,04 \mathrm{cA}$ \\
Adubo de galinha & $3,64 \pm 0,07 \mathrm{aC}$ & $3,59 \pm 0,05 \mathrm{aA}$ & $3,97 \pm 0,05 \mathrm{bB}$ & $4,18 \pm 0,04 \mathrm{cA}$ \\
Adubo de gado & $3,23 \pm 0,08 \mathrm{aB}$ & $3,54 \pm 0,06 \mathrm{bA}$ & $3,85 \pm 0,05 \mathrm{cB}$ & $4,17 \pm 0,05 \mathrm{dA}$ \\
\hline
\end{tabular}

1 Valores seguidos de letras minúsculas iguais na linha e de letras maiúsculas iguais na coluna, não diferem significativamente a $5 \%$ pelo teste de Tukey; $\mathrm{F}$ tratamento $=44,01^{* *} ; \mathrm{F}$ adubo $=24,88^{* *} ; \mathrm{F}$ profundidade $=122,32^{* *} ; \mathrm{F}$ adubo $\mathrm{x}$ prof. $=11,24^{* *} ; \mathrm{C} . \mathrm{V} .(\%)=21,56$.

${ }^{* *}$ Significativo a $1 \%$.

TABELA 4. Índice de velocidade de emergência (IVE) de Brassica chinensis var. parachinensis (média \pm erro padrão), em diferentes condições de campo ${ }^{1}$.

\begin{tabular}{|c|c|c|c|c|}
\hline \multirow[t]{2}{*}{ Adubação } & \multicolumn{4}{|c|}{ Profundidade de semeadura $(\mathrm{cm})$} \\
\hline & 0,5 & 1,0 & 1,5 & 2,0 \\
\hline Mineral & $17,43 \pm 0,73 \mathrm{aA}$ & $14,28 \pm 1,12 \mathrm{bA}$ & $14,19 \pm 0,70 \mathrm{bA}$ & $10,72 \pm 0,50 \mathrm{cA}$ \\
\hline Esterco de galinha & $8,82 \pm 0,71 \mathrm{aB}$ & $9,56 \pm 1,19 \mathrm{aB}$ & $8,65 \pm 1,40 \mathrm{aB}$ & $9,98 \pm 0,49 \mathrm{aA}$ \\
\hline Esterco de gado & $7,63 \pm 0,40 \mathrm{bB}$ & $11,70 \pm 0,70 \mathrm{aAB}$ & $10,63 \pm 0,34 \mathrm{abB}$ & $8,54 \pm 0,69 \mathrm{bA}$ \\
\hline
\end{tabular}

TABELA 5. Emergência de plântulas de Brassica chinensis var. parachinensis (média \pm erro padrão) em condições de campo, sete dias após a instalação do experimento ${ }^{1}$.

\begin{tabular}{|c|c|c|c|c|c|c|c|c|}
\hline \multirow[t]{3}{*}{ Adubação } & \multicolumn{8}{|c|}{ Profundidade de semeadura $(\mathrm{cm})$} \\
\hline & \multicolumn{2}{|c|}{0,5} & \multicolumn{2}{|c|}{1,0} & \multicolumn{2}{|c|}{1,5} & \multicolumn{2}{|c|}{2,0} \\
\hline & $\%$ & v.a. $^{2}$ & $\%$ & v.a. $^{2}$ & $\%$ & v.a. $^{2}$ & $\%$ & v.a. $^{2}$ \\
\hline Mineral & $92,8 \pm 3,14$ & $77,92 \mathrm{aA}$ & $89,2 \pm 5,82$ & $75,50 \mathrm{aA}$ & $96,4 \pm 1,47$ & $81,49 \mathrm{aA}$ & $84,8 \pm 2,33$ & $67,39 \mathrm{aA}$ \\
\hline Esterco de galinha & $61,6 \pm 4,58$ & $51,84 \mathrm{aB}$ & $73,6 \pm 5,67$ & $59,58 \mathrm{aB}$ & $66,0 \pm 11,66$ & $57,74 \mathrm{aB}$ & $80,8 \pm 2,80$ & $64,21 \mathrm{aA}$ \\
\hline Esterco de gado & $48,8 \pm 4,45$ & $44,27 \mathrm{bB}$ & $78,8 \pm 6,83$ & $63,88 \mathrm{aAB}$ & $79,6 \pm 2,14$ & $63,27 \mathrm{aB}$ & $71,2 \pm 5,16$ & $57,93 \mathrm{abA}$ \\
\hline
\end{tabular}

1 Valores seguidos de letras minúsculas iguais na linha e de letras maiúsculas iguais na coluna, não diferem significativamente a 5\% pelo teste de Tukey; $\mathrm{F}$ adubo $=20,66^{* *} ; \mathrm{F}$ profundidade $=2,65 ; \mathrm{F}$ adub. $\mathrm{x}$ prof. $=2,24 ; \mathrm{C} . \mathrm{V} .(\%)=15,82$.

2 Valor angular; dados transformados em arco seno para análise.

*** Significativo a $1 \%$. 
aumentar a superfície de contato da semente com o solo. Além disso, a disponibilidade mais rápida de nutrientes propicia maior velocidade de emergência das plântulas.

Segundo Nieuwhof(1969), a profundidade de semeadura ótima para couves, em geral, está entre 1,5 e $3,0 \mathrm{~cm}$, e solos ricos em nitrogênio estimulam o crescimento das plântulas. Em condições ambientais ótimas as plântulas das couves chinesas emergem do solo em três a quatro dias (Opeña et al., 1988). Tais informações indicam que a germinação das sementes de couve-da-malásia nesses primeiros cultivos em campo, no Brasil, está dentro dos padrões gerais citados na literatura.

\section{Morfologia de plântulas produzidas em laboratório}

O comprimento do hipocótilo e da raiz primária de plântulas oriundas de sementes tratadas com solução de hipoclorito de sódio foram significativamente menores que nos demais tratamentos, em condições de laboratório (Tabela 6). Isso mostra que apesar de o hipoclorito de sódio não ter exercido efeito drástico na germinação das sementes, sua ação negativa se manifestou na morfologia das plântulas. O siste-

TABELA 6. Comprimento do hipocótilo e da raiz primária de plântulas de Brassica chinensis var. parachinensis, mantidas em condições de laboratório, sete dias após a instalação do experimento ${ }^{1}$.

\begin{tabular}{lcc}
\hline Tratamentos & $\begin{array}{c}\text { Hipocótilo }^{2} \\
\left(\mathrm{~mm}^{2}\right)\end{array}$ & $\begin{array}{c}\text { Raiz primária } \\
\left(\mathrm{mm}^{2}\right)\end{array}$ \\
\hline $\mathrm{KNO}_{3}$ & $11,91 \pm 0,53 \mathrm{a}$ & $32,72 \pm 1,88 \mathrm{~b}$ \\
$\mathrm{GA}_{3} 0,001 \mu \mathrm{g} / \mathrm{mL}$ & $10,60 \pm 0,56 \mathrm{a}$ & $36,31 \pm 1,68 \mathrm{~b}$ \\
Estratificação 24 horas & $10,32 \pm 0,62 \mathrm{a}$ & $47,34 \pm 1,32 \mathrm{a}$ \\
Água (controle) & $9,68 \pm 0,53 \mathrm{a}$ & $37,80 \pm 1,66 \mathrm{~b}$ \\
Hipoclorito de sódio & $7,26 \pm 0,72 \mathrm{~b}$ & $10,04 \pm 1,68 \mathrm{c}$ \\
\hline F & $9,08^{* *}$ & $80,68^{* *}$ \\
G.L. & $4 ; 95$ & $4 ; 95$ \\
C.V. (\%) & 14,54 & 13,43 \\
\hline
\end{tabular}

1 Valores seguidos de letras iguais na coluna, não diferem significativamente a $5 \%$ pelo teste de Tukey.

${ }^{2}$ Média \pm erro padrão; dados transformados em raiz quadrada para análise.

** Significativo a $1 \%$. ma subterrâneo reduzido compromete o estabelecimento bem-sucedido dessas, por falta de sustentação no solo; a inibição do hipocótilo impede uma rápida emergência, o que é suficiente para não se recomendar a utilização da substância, com 0,14\% de cloro ativo, como forma de assepsia das sementes ou como agente de escarificação. Como o tegumento da semente é fino, células embrionárias importantes para o desenvolvimento normal da plântula podem ter sido afetadas.

O maior comprimento da raiz primária das plântulas foi alcançado quando as sementes foram estratificadas por 24 horas (Tabela 6). Essa resposta pode estar relacionada com o centro de origem e de domesticação da espécie, em regiões mais frias e montanhosas do Mediterrâneo.

\section{CONCLUSÕES}

1. As sementes de Brassica chinensis var. parachinensis apresentam germinação alta e sincronizada.

2. A assepsia das sementes com hipoclorito de sódio com $0,14 \%$ de cloro ativo causa redução da germinabilidade em $12 \%$ e compromete a morfologia da plântula.

3. A melhor profundidade de semeadura situa-se entre 1,0 e $1,5 \mathrm{~cm}$.

\section{AGRADECIMENTOS}

Ao Dr. Warwick Estevan Kerr, pelo fornecimento das sementes; ao Dr. Luiz Ricardo Goulart Filho, pela revisão do Abstract; à Prof ${ }^{\mathrm{a}}$ Denise Santana, pela orientação no tratamento estatístico dos dados; e ao Dr. Fernando A. R. Filgueira, pela leitura crítica do texto e sugestões.

\section{REFERÊNCIAS}

BAILEY, L.H. The cultivated brassicas. Gentes Herbarum, v.2, n.5, p.209-267, 1930.

BANZATTO, D.A.; KRONKA, S.N. Experimentação agrícola. Jaboticabal: FCAV/FUNEP, 1989. 247p.

BEWLEY, J.D.; BLACK, M. Physiology and biochemistry of seeds in relation to germination:

Pesq. agropec. bras., Brasília, v.34, n.3, p.353-361, mar. 1999 
viability, dormancy, and environmental control. New York: Springer-Verlag, 1982. v.2, 375p.

BEWLEY, J.D.; BLACK, M. Seeds: physiology of development and germination. 2.ed. New York: Plenum Press, 1994. 445p.

CARNELOSSI, M.A.G.; LAMOUNIER, L.; RANAL, M.A. Efeito da luz, hipoclorito de sódio, escarificação e estratificação na germinação de sementes de alface (Lactuca sativa L.), cv. Maioba e Moreninha-deUberlândia. Pesquisa Agropecuária Brasileira, v.30, n.6, p.779-787, jun. 1995.

COBBE, R.V.; JABUONSKI, R.E. A importância econômica e social das plantas olerícolas. In: FERREIRA, M.E.; CASTELLANE, P.D.; CRUZ, M.C.P. (Eds.). Nutrição e adubação de hortaliças. Piracicaba: POTAFOS, 1993. p.1-14.

COSTA, M.T.P.M.; RESENDE, L.M.A. Algumas estatísticas sobre brássicas em Minas Gerais. Informe Agropecuário. Belo Horizonte, v.9, n.98, p.3-10, fev. 1983.

DREW, R.L.K.; BROCKLEHURST, P.A. The effect of sodium hypochlorite on germination of lettuce seed at high temperature. Journal of Experimental Botany, v.35, n.156, p.975-985, 1984.

ELLIS, R.H.; HONG, T.D.; ROBERTS, E.H. Quantal response of seed germination in seven genera of Cruciferae to white light of varying photon flux density and photoperiod. Annals of Botany, v.63, p.145-158, 1989.

EMAL, J.G.; CONARD, E.C. Seed dormancy and germination in indian grass as affected by light, chilling, and certain chemical treatments. Agronomy Journal, v.65, p.383-385, 1973.

FILGUEIRA, F.A.R. Manual de olericultura: cultura e comercialização de hortaliças. Olericultura Especial. 2.ed. ampl. e rev. São Paulo: Agronômica Ceres, 1982. v. $2,357 \mathrm{p}$.

FRANK, A.B.; LARSON, K.L. Influence of oxygen, sodium hypochlorite, and dehulling on germination of green needlegrass seed (Stipa viridula Trin.). Crop Science, v.10, p.679-682, 1970.

FRENCH, R.C.; SHERMAN, L.J. Factors affecting dormancy, germination, and seedling development of Aeginetia indica L. (Orobanchaceae). American Journal of Botany, v.63, n.5, p.558-570, 1976.
GÓMEZ-CAMPO, C. Morphology and morphotaxonomy of the tribe Brassiceae. In: TSUNODA, S.; HINATA, K.; GÓMEZ-CAMPO, C. (Eds.). Brassica crops and wild allies: biology and breeding. Tokyo: Japanese Scientific Societies Press, 1980. p.3-31.

HERKLOTS, G.A.C. Vegetable in South-East Asia. Hong Kong: George Allen \& Unewin Ltda, 1972. $525 \mathrm{p}$.

HILHORST, H.W.M. Dose-response analysis of factors involved in germination and secondary dormancy of seeds of Sisymbrium officinale. I. Phytochrome. Plant Physiology, v.94, p.1090-1095, 1990a.

HILHORST, H.W.M. Dose-response analysis of factors involved in germination and secondary dormancy of seeds of Sisymbrium officinale. II. Nitrate. Plant Physiology, v.94, p.1096-1102, 1990b.

HILL, T.R. The effect of nitrogenous fertilizer and plant spacing on the yield of three Chinese vegetables Kai lan, Tsoi sum and Pak choi. Scientia Horticulturae, v.45, p.11-20, 1990.

HSIAO, A.I. The effect of sodium hypochlorite and gibberellic acid on seed dormancy and germination of wild oats (Avena fatua). Canadian Journal of Botany, v.57, p.1729-1734, 1979.

HSIAO, A.I.; WORSHAM, A.D.; MORELAND, D.E. Effects of sodium hypochlorite and certain plant growth regulators on germination of witchweed (Striga asiatica) seeds. Weed Science, v.29, n.1, p.98-100, 1981.

KIMOTO, T. Nutrição e adubação de repolho, couve-flor e brócolo. In: FERREIRA, M.E.; CASTELLANE, P.D.; CRUZ, M.C.P. (Eds.). Nutrição e adubação de hortaliças. Piracicaba: POTAFOS, 1993. p.149178.

LABOURIAU, L.G. A germinação das sementes. Washington, DC: OEA - Prog. Reg. Desenv. Cient. Tecnol., 1983. 174p. (Biologia. Monografia, 24).

LEE, S.-H. Vegetable crops growing in China. Scientia Horticulturae, v.17, p.201-209, 1982.

MAGUIRE, J.D. Speed of germination-aid in selection and evaluation for seedling emergence and vigor. Crop Science, v.2, n.2, p.176-177, 1962.

McCOLlUM, J.P.; LINN, M.B. Bleaching and disinfecting discolored pepper seed with sodium hypochlorite. Proceedings of the American 
Society for Horticultural Science, v.66, p.345349,1955

NIEUWHOF, M. Cole crops: botany, cultivation, and utilization. London: Leonard Hill, 1969. 353p.

NISHI, S. Differentiation of Brassica crops in Asia and the breeding of 'Hakuran', a newly synthesized leafy vegetable. In: TSUNODA, S.; HINATA, K.; GÓMEZ-CAMPO, C. (Eds.). Brassica crops and wild allies: biology and breeding. Tokyo: Japanese Scientific Societies Press, 1980. p.133-150.

OKONKWO, S.N.C.; NWOKE, F.I.O. Bleach-induced germination and breakage of dormancy of seeds of Alectra vogelii. Physiologia Plantarum, v.35, p.175-180, 1975.

OPEÑA, R.T.; KUO, C.G.; YOON, J.Y. Breeding and seed production of Chinese cabbage in the Tropics and Subtropics. Tainan, Taiwan: Asian Vegetable Research and Development Center, 1988. 92p. (Technical Bulletin, 17).

SCHIAVINI, I. Estrutura das comunidades arbóreas de mata de galeria da Estação Ecológica do Panga (Uberlândia, MG). Campinas: UNICAMP, 1992. 139p. Tese de Doutorado.

SOLANKI, S.S.; JOSHI, R.P. Studies on invigoration of vegetable seeds of tomato (Lycopersicum esculentum) and cauliflower (Brassica oleracea L.). Progressive Horticulture, v.17, n.3, p.267-269, 1985.

VILELLA, M.R. Brássicas, hortaliças de alto valor alimentício. Informe Agropecuário. Belo Horizonte. v.9, n.98, p.1, fev. 1983. 